\title{
Combinatorial optimization and synthesis of multiple promoted MoVNbTe catalysts for oxidation of propane to acrylic acid.
}

András Tompos ${ }^{\mathrm{c}}$, Maricruz Sanchez-Sanchez ${ }^{\mathrm{d}}$, Lajos Végvári ${ }^{\mathrm{b}}$, Gábor P. Szijjártóc ${ }^{\mathrm{c}}$, József L. Margitfalvi $^{\mathrm{b}}$, Annette Trunschke ${ }^{\mathrm{e}}$, Robert Schlögl ${ }^{\mathrm{e}}$, Klaus Wanninger $^{\mathrm{a}}$, and Gerhard Mestl ${ }^{\mathrm{a} 1}$,

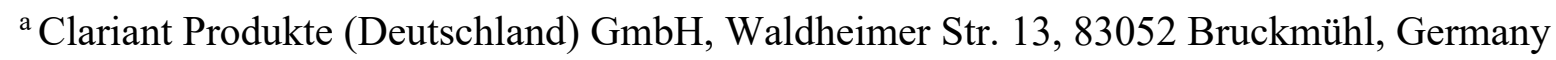

${ }^{\mathrm{b}}$ Combitech-Nanotech Ltd., Magyar jakobinusok tere 7, 1122 Budapest, Hungary

${ }^{\mathrm{c}}$ Institute of Materials and Environmental Chemistry, Research Centre for Natural Sciences, Hungarian Academy of Sciences, POB 17, 1525 Budapest, Hungary

${ }^{\mathrm{d}}$ Department of Chemistry and Catalysis Research Center, Technical University Munich, Lichtenbergstraße 4, 85748 Garching (Germany)

${ }^{\mathrm{e}}$ Department of Inorganic Chemistry, Fritz-Haber-Institut der Max-Planck-Gesellschaft, Faradayweg 4-6, 14195 Berlin (Germany)

\begin{abstract}
New MoVTeNb multi-component catalysts (so-called M1 phase) were designed and tested using combinatorial and high-throughput methods. An international team of academic institutes and industrial partners has cooperated to understand the chemistry occurring during the hydrothermal synthesis and crystallization of the M1 phase of the MoVTeNb mixed oxide. With this information, the optimization of this catalyst system could be targeted with the aim of improving catalyst performance for short chain alkane - ethane and propane - oxidation reactions.

Beside the elements responsible for the formation of the M1 phase (Mo, V, Te, and $\mathrm{Nb}$ ) and promoters found to be advantageous in our previous work ( $\mathrm{Mn}, \mathrm{Ni}, \mathrm{W}$ and citric acid), the following components were added to the synthesis mixture: $\mathrm{Ce}, \mathrm{Cu}, \mathrm{Co}, \mathrm{Cr}$ and ethylene glycol. Contrary to the previous approach in this study, the $\mathrm{V} / \mathrm{Mo}, \mathrm{Te} / \mathrm{Mo}$ and $\mathrm{Nb} / \mathrm{Mo}$ ratios were kept constant. Consequently, the experimental space had nine variables. The discrete levels of variables are established in such a way that the number of the potential experimental points in the multi-dimensional experimental space was in the range of 200000 . Five new generations were designed using an optimization platform consisting of holographic optimization algorithm
\end{abstract}

\footnotetext{
${ }^{1}$ Corresponding author: Tel: +49 80614903 825; E-mail address: Gerhard.Mestl@clariant.com
} 
and artificial neural networks. Altogether 250 catalysts were prepared and tested. A complex objective function was created consisting of two independent catalytic performance characteristics - conversion and product selectivity - as well as the expected production costs and prices of the target product acrylic acid (AA) and export steam. The AA production costs were estimated assuming a recycle scheme for such a future AA plant with standard downstream equipment. The best catalysts in the group of catalysts with low vanadium content gave acrylic acid yields of $58 \%$ in the high throughput tests after five generations. On the bases of holographic maps, correlations between the composition of the synthesis mixtures and the yields of AA were visualized allowing to see the cross effect between components. Mn and Co had a positive effect, while $\mathrm{Cu}$ and $\mathrm{Ce}$ resulted in negative effect on the yield of AA. The analysis of the correlation between conversions vs. product yields allowed figuring out the main reaction routes leading to acrylic acid and $\mathrm{CO}_{2}$ in a consecutive reaction scheme.

Following this successful high throughput development, the hydrothermal method using the newly identified synthesis aids was further optimized and successfully scaled up to 401 autoclaves using the cheapest available chemicals, the oxides. This now renders possible the large-scale production of that complex MoVNbTe mixed oxide catalyst.

Keywords: alkane oxidation, selective oxidation, oxidative dehydrogenation, acrylic acid, Mo based multi-metal oxide catalyst, MoVNbTe oxide, combinatorial method, high-throughput experimentation, hydrothermal synthesis, scale-up.

\section{Introduction}

We dedicate this contribution to our friend and mentor Robert K. Grasselli who was and still is one of the most influencing scientists in the field of selective partial oxidations. He was one of the inventors of the SOHIO technology [1-3] in the 60ties and 70ties of last century and he remained active in this field for his whole life [4]. The classical technology is based on the use of propene in a two-stage oxidation process, in which first propene is oxidized to acrolein, followed by the oxidation of acrolein to acrylic acid. In this classical two-stage propene-based process selectivity values for acrylic acid above $90 \%$ were achieved [5-6]. Today all acrylic acid plants are using this two-stage process. This process is based on the use of Mo based multimetal oxide catalysts with several promoters for optimum selectivity. 
There are several new routes to acrylic, like Cargill's sugar fermentation to hydroxyl propionic acid [7], and its dehydration to acrylic acid. Arkema has developed a new route to acrylic acid starting from glycerol [8]. There is another pathway to acrylic acid using propane which is oxidized in a one-step reaction to acrylic acid. It has been found that a Mo-based multi-metal oxide containing vanadium, niobium and tellurium is the most active and selective catalyst, and the presence of the so-called crystalline M1 structure is mandatory for high performance [919]. During the last 30 years, Robert K. Grasselli dedicated himself to the understanding and development of this, so-called M1 catalyst, a Mo-based mixed metal oxide additionally containing $\mathrm{V}, \mathrm{Nb}$ and $\mathrm{Te}$ ions, for partial oxidation of short chain alkanes, ethane and propane [20]. Still, after ca. 1220 papers and patents it is unknown in detail how the active and selective centers might look like on the different exposed surfaces of this complex oxide and how the catalytic reaction occurs on an atomic level.

Propene is mainly used for polypropylene and acrylonitrile, both markets growing strongly. The hence expected price increase and shortage of propene in the future [21], is the driving force for the development of this alternative process. Furthermore, it is assumed that propane will be increasingly available in the future from shale gas exploitation. Arkema for example developed this M1 type catalyst for a moving bed process. Best results were obtained in the temperature regime between 350 to $440{ }^{\circ} \mathrm{C}$ and with residence times from 0.1 to $30 \mathrm{~s}$ [22]. In the process developed by BASF, propane is dehydrogenated first to propene, and the resulting mixture of propene and propane is fed to the classical 2-stage reactor setup [23]. Very recently, Taogosei Co. Ltd. announced to commercialize an industrial scale process making acrylic acid from propane in a one-step reaction using a new single type, three-in-one catalyst for dehydrogenation and two-step oxidation. They designed a mid-sized demonstration facility with reaction tubes of the same size as those in a commercial-scale unit and achieved a yield of $65 \%$ in a one-pass flow reaction [24].

Such Mo-based mixed metal oxides also have been identified too as being very active and selective in the oxidative dehydrogenation of ethane to ethene which promoted activities to develop respective processes [25-55]. Consequently, there is a permanent interest to develop further improved catalyst systems based on M1.

Two families of MoVTeNb oxide catalysts have been identified in our previous study [56], one with low the other with high vanadium contents. This study now reports results mainly on the family with low vanadium content. Our research was focused on a) the fundamental understanding of the synthesis chemistry of this complex oxide, b) its compositional phase space with respect to the main constituting elements, and c) its optimization by addition of 
different new components. The optimization was done by means of a combinatorial and highthroughput research concept based on so-called holographic research strategy (HRS) in combination with artificial neural networks (ANNs) [57-59]. Starting from there, our target was further to transfer the best identified synthesis route into the industrial environment, to optimize the synthesis for technical starting chemicals, to scale-up and fine tune the synthesis route into the $\mathrm{kg}$ regime thus allowing the development of shaped catalysts for real size reactor dimensions.

\section{Materials and Methods}

\subsection{Preparation of catalysts}

\subsubsection{Synthesis parameter space studies}

For the study of the synthesis parameter space, MoVTeNb mixed oxides were prepared by hydrothermal synthesis following the procedure described somewhere else [60]. The molar ratio of the different metals was fixed at $\mathrm{Mo} / \mathrm{V} / \mathrm{Te} / \mathrm{Nb}=1 / 0.25 / 0.23 / 0.12$. The initial aqueous mixture was prepared by successive dissolution of $11.75 \mathrm{~g}(9.51 \mathrm{mmol})\left(\mathrm{NH}_{4}\right)_{6} \mathrm{Mo}_{7} \mathrm{O}_{24}(\mathrm{Merck}$, $81-83 \%$ as $\mathrm{MoO}_{3}$ ), $3.86 \mathrm{~g}$ (16.6 mmol) $\mathrm{VOSO}_{4} \cdot 5 \mathrm{H}_{2} \mathrm{O}$ (Alfa Aesar, 99.9\%), $3.52 \mathrm{~g}$ (15.3 mmol) $\mathrm{Te}(\mathrm{OH})_{6}$ (Fluka, > $99.0 \%$ ), and $3.80 \mathrm{~g}(7.94 \mathrm{mmol}) \mathrm{NH}_{4}\left[\mathrm{NbO}\left(\mathrm{C}_{2} \mathrm{O}_{4}\right)_{2}\right] \cdot 9.7 \mathrm{H}_{2} \mathrm{O}$ (H.C. Starck $99.99 \%$ ) in $230 \mathrm{ml}$ ultrapure water. The water was purified using the Milli-Q Synthesis System (MQ). First, ammonium heptamolybdate was dissolved at $40{ }^{\circ} \mathrm{C}$ in $200 \mathrm{ml}$ $\mathrm{H}_{2} \mathrm{O}$, followed by addition of solid vanadyl sulfate. After $15 \mathrm{~min}$ stirring at $400 \mathrm{rpm}, \mathrm{Te}(\mathrm{OH})_{6}$ was added in solid form and the suspension was heated up to $80^{\circ} \mathrm{C}$ and stirred for $20 \mathrm{~min}$. Ammonium niobate (V) oxalate hydrate dissolved at $40{ }^{\circ} \mathrm{C}$ in $30 \mathrm{ml}$ water was added after cooling down the Mo-V-Te mixture to $40^{\circ} \mathrm{C}$. In order to homogenize the MoVNbTe synthesis gel, stirring was continued at $40{ }^{\circ} \mathrm{C}$ for another $30 \mathrm{~min}$.

The mixture was charged into an analytic autoclave HPM-PT-040 (400 ml) made of Hastelloy C22 (Premex Reactor GmbH). A thermostatic oil circulating in a double shell mantle heats the unit. Hydrothermal synthesis was performed at temperatures ranging from $180-220^{\circ} \mathrm{C}$ (heating ramp $5{ }^{\circ} \mathrm{C} / \mathrm{min}$, cooling ramp $1.6^{\circ} \mathrm{C} / \mathrm{min}$ ) under autogenous pressure (ranging from 14 bar to 28 bar respectively for the lower and upper temperature limit), applying a stirring rate of $250 \mathrm{rpm}$. Catalyst precursor materials were prepared applying hydrothermal reaction times between 1 and $48 \mathrm{~h}$.

Suspensions obtained after hydrothermal synthesis were separated by centrifugation at $3600 \mathrm{rpm}$ for $10 \mathrm{~min}$. The solid fractions were washed with $100 \mathrm{ml}$ of $\mathrm{H}_{2} \mathrm{O}$ and then centrifuged 
again at $3600 \mathrm{rpm}$ for $30 \mathrm{~min}$. Finally, washed solids were dried at $80{ }^{\circ} \mathrm{C}$ for $16 \mathrm{~h}$ to obtain the precursor oxides. Thermal treatment of precursors was done in a rotary tube furnace (Xerion) under Ar flow $\left(100 \mathrm{ml} / \mathrm{min}\right.$ ) at $600-650{ }^{\circ} \mathrm{C}$ (heating rate $15^{\circ} \mathrm{C} / \mathrm{min}$ ) for $2 \mathrm{~h}$.

\subsubsection{High throughput optimization (Synthesis)}

The catalysts have been prepared in a parallel way by means of microwave assisted hydrothermal synthesis in a microwave (MW) oven equipped with 16 Teflon lined autoclaves (Synthos 3000, Anton Paar). The following precursors and chemicals were used: $\mathrm{MoO}_{3}, \mathrm{~V}_{2} \mathrm{O}_{5}$, $\mathrm{Te}(\mathrm{OH})_{6}, \quad\left(\mathrm{NH}_{4}\right)\left(\mathrm{NbO}\left(\mathrm{C}_{2} \mathrm{O}_{4}\right)_{2}\left(\mathrm{H}_{2} \mathrm{O}\right)_{2}\right) * 3 \mathrm{H}_{2} \mathrm{O}, \quad \mathrm{Mn}\left(\mathrm{NO}_{3}\right)_{2} * 4 \mathrm{H}_{2} \mathrm{O}, \quad \mathrm{Ni}\left(\mathrm{NO}_{3}\right)_{2} * 6 \mathrm{H}_{2} \mathrm{O}, \quad \mathrm{WO}_{3}$, $\mathrm{Cu}\left(\mathrm{NO}_{3}\right)_{2} * 3 \mathrm{H}_{2} \mathrm{O}, \mathrm{Cr}\left(\mathrm{NO}_{3}\right)_{3} * 9 \mathrm{H}_{2} \mathrm{O}, \mathrm{Co}\left(\mathrm{NO}_{3}\right)_{2} * 6 \mathrm{H}_{2} \mathrm{O}$ ethylene glycol (EG) and citric acid (AA). The amount of Mo was fixed at $25 \mu \mathrm{mol}$ and molar ratios $\mathrm{V}, \mathrm{Nb}$ and $\mathrm{Te}$ to Mo were set at 0.22 , 0.18 and 0.18 , respectively. All other components have been added in the required amounts prescribed by HRS optimization algorithm. Precursors of $\mathrm{Mo}, \mathrm{V}, \mathrm{Te}, \mathrm{Ni}, \mathrm{Cu}, \mathrm{Cr}, \mathrm{Co}$, and $\mathrm{W}$ have been mixed and pulverized manually in an agate mortar. The Nb-precursor has been dissolved in water leading to an aqueous solution of $0.4 \mathrm{~mol} \mathrm{Nb} / \mathrm{dm}^{3}$ concentration. The required amount of Mn-precursor, ethylene glycol and citric acid, according to HRS algorithm, have been added in appropriate volumes to this solution.

The solid mixtures (Mo, V, Te, Ni, Cu, Cr, Co) and the solutions ( $\mathrm{Nb}, \mathrm{Mn}$, citric acid, glycol) were unified according to the following steps. First, the solid mixtures were loaded into the Teflon autoclaves of the MW-oven. The analytically complete removal of the powders from the small crucibles was achieved by washing the crucibles with $10 \mathrm{ml}$ deionized water (18 MOhm). In the next step, the solutions were added. Complete removal of the solutions from the reaction glasses was performed by means of washing the reaction glasses with $10 \mathrm{ml}$ deionized water (18 MOhm). Finally, $18.75 \mathrm{ml}$ deionized water (18 MOhm) was added to the synthesis mixtures, which led to filling up the Teflon autoclaves up to half of their total volumes.

The Teflon autoclaves have been purged with nitrogen for 2 minutes with ca. $100 \mathrm{ml} / \mathrm{min}$ flow rate. After closing the Teflon autoclaves the initial pressure of nitrogen was between 3-6 bars. Hydrothermal synthesis was performed under vigorous stirring at $175^{\circ} \mathrm{C}$ for 180 minutes. Additional details of synthesis procedures are given in our previous study [56].

\subsubsection{High throughput optimization (library design)}

The general scheme of our approach has been given in ref [61,62]. Briefly, the analysis of the catalyst performances in preceding generations provides the feedback to the design the next 
generation. In the first generation, the number of variables was nine. Based on analysis by ANNs and PLS the number of components were reduced to seven in the $2^{\text {nd }} / 3^{\text {rd }}$ and to five in the $4^{\text {th }} / 5^{\text {th }}$ generations, respectively. The variable levels in different generations are given in Tables 1, 2, 3. Accordingly, the experimental spaces explored consisted of 110592, 32400, and 960 potential experiments in the first, second/third and fourth/fifth generations, respectively. The results of ANNs analysis were visualized using holographic mapping technique [63]. The component levels used in holographic mapping are given in Table 4. In this approach only the most important five components were considered.

\subsubsection{Synthesis scale-up trials into the kg-regime}

Several scale-up trials have been executed in order to optimize the synthesis route. In a first step, the regularly used telluric acid was exchanged for tellurium dioxide having a particle size distribution of $\mathrm{d}_{10}=7.625 \mu \mathrm{m}, \mathrm{d}_{50}=15.14 \mu \mathrm{m}$, and $\mathrm{d}_{90}=27.409 \mu \mathrm{m} .3 .31$ deionized water was filled into the 401 autoclave and heated at $80{ }^{\circ} \mathrm{C}$ while stirring. During heating, $725.58 \mathrm{~g}$ ammonium heptamolybdate (AHM) (HC Starck) were added and dissolved. Two times 1.651 deionized water were filled into 2.51 beakers and heated too at $80{ }^{\circ} \mathrm{C}$ while being stirred using a magnetic stirrer. $405.10 \mathrm{~g}$ vanadyl sulfate hydrate $(\mathrm{GfE}, \mathrm{V}$ content $=21.2 \%)$ were added and dissolved in one beaker, while $185.59 \mathrm{~g}$ of ammonium niobium oxalate (HC Starck, $\mathrm{Nb}$ content $=20.6 \%$ ) were added and dissolved in the other beaker. The vanadium solution was pumped first into the AHM solution within 4.5 min using a peristaltic pump with a hose of $8 \times 5 \mathrm{~mm}$ at $190 \mathrm{rpm}$, followed by the addition of $65.59 \mathrm{~g}$ solid $\mathrm{TeO}_{2}$ powder (Alfa Aesar, $5 \mathrm{~N}+$ ) and 1.651 deionized water. The suspension was stirred at $80{ }^{\circ} \mathrm{C}$ for $1 \mathrm{~h}$. Then, the $\mathrm{Nb}$ solution was pumped into the 401 autoclave within 6 min using again a peristaltic pump at $130 \mathrm{rpm}$ with a hose of $8 \times 5 \mathrm{~mm}$. The suspension formed was stirred at $90 \mathrm{rpm}$ for another $10 \mathrm{~min}$ at $80^{\circ} \mathrm{C}$. Subsequently, the autoclave was purged with $\mathrm{N}_{2}$ at a pressure of 6 bar for $5 \mathrm{~min}$ and afterwards, the pressure was reduced to 1 bar. The hydrothermal treatment in the 401 autoclave was conducted at $175^{\circ} \mathrm{C}$ (heating time to reaction temperature was $3 \mathrm{~h}$ ) for $20 \mathrm{~h}$ using an anchor stirrer at $90 \mathrm{rpm}$. After synthesis, the suspension was pumped into a vacuum tank filter with a blue band filter and filtered using a vacuum pump. The filter cake was washed with 51 deionized water and dried at $80^{\circ} \mathrm{C}$ in a drying cabinet for 3 days. Subsequently, the dried powder was milled with an impact mill giving $0.8 \mathrm{~kg}$ powder. The powder was calcined at $280{ }^{\circ} \mathrm{C}$ (heating rate $=5 \mathrm{~K} / \mathrm{min}$ ) in flowing air of $1 \mathrm{l} / \mathrm{min}$ for $4 \mathrm{~h}$. The activation was conducted in a reactor at $600{ }^{\circ} \mathrm{C}$ (heating rate $5 \mathrm{~K} / \mathrm{min}$ ) in flowing $\mathrm{N}_{2}$ of $0.5 \mathrm{l} / \mathrm{min}$ for $2 \mathrm{~h}$. 
In the second step of the scale-up, only oxides have been used for the synthesis of the M1 matrix, as they would be the cheapest available starting materials for production. $\mathrm{TeO}_{2}$ (Alfa Aesar) was suspended in $200 \mathrm{~g}$ deionized water and milled with a planetary ball mill with $1 \mathrm{~cm}$ $\mathrm{ZrO}_{2}$ balls. Subsequently, the milled suspension was transferred with $500 \mathrm{ml}$ deionized water into a beaker. $\mathrm{Nb}_{2} \mathrm{O}_{5}(\mathrm{CBMM})$ was suspended in $200 \mathrm{~g}$ deionized water and milled using the same planetary mill. Again, the obtained suspension was transferred with $500 \mathrm{ml}$ water into a beaker. The $\mathrm{Nb}$-suspension was heated at $80^{\circ} \mathrm{C}$, and $107.8 \mathrm{~g}$ oxalic acid dihydrate was added and stirred for $1 \mathrm{~h} .61$ deionized water was filled into the 401 autoclave and heated at $80{ }^{\circ} \mathrm{C}$ while stirring with $90 \mathrm{rpm}$. After reaching the reaction temperature, $61.58 \mathrm{~g}$ citric acid, $19.9 \mathrm{~g}$ ethylene glycol, $615.5 \mathrm{~g} \mathrm{MoO}_{3}$ (Sigma Aldrich), $124.5 \mathrm{~g} \mathrm{~V}_{2} \mathrm{O}_{5}$, the milled $\mathrm{TeO}_{2}$ suspension, and finally the milled $\mathrm{Nb}_{2} \mathrm{O}_{5}$ in oxalic acid were filled into the autoclave. $850 \mathrm{ml}$ deionized water was used to transfer all starting materials and to rinse the used beakers. The total amount of $\mathrm{H}_{2} \mathrm{O}$ in the autoclave was 8.251 . Subsequently, the autoclave was purged with $\mathrm{N}_{2}$. The hydrothermal treatment was conducted at $190{ }^{\circ} \mathrm{C}$ for $48 \mathrm{~h}$. After synthesis, the suspension was pumped into a vacuum tank filter with a blue band filter and filtered using a vacuum pump. The filter cake was washed with 51 deionized water and dried at $80{ }^{\circ} \mathrm{C}$ in a drying cabinet for 3 days. Subsequently, the dried powder was milled with an impact mill giving $0.8 \mathrm{~kg}$ powder. The powder was calcined at $280{ }^{\circ} \mathrm{C}$ (heating rate $=5 \mathrm{~K} / \mathrm{min}$ ) in flowing air of $1 \mathrm{l} / \mathrm{min}$ for $4 \mathrm{~h}$. The activation was conducted in a reactor at $600{ }^{\circ} \mathrm{C}$ (heating rate $5 \mathrm{~K} / \mathrm{min}$ ) in flowing $\mathrm{N}_{2}$ of $0.5 \mathrm{l} / \mathrm{min}$ for $2 \mathrm{~h}$.

\subsection{Characterization Methods}

A Pioneer S4 (Bruker AXS GmbH) X-Ray Fluorescence spectrometer was used for chemical analysis. The samples and corresponding standards composed of $\mathrm{MoO}_{3}, \mathrm{~V}_{2} \mathrm{O}_{5}, \mathrm{Nb}_{2} \mathrm{O}_{5}$, and $\mathrm{Te}(\mathrm{OH})_{6}$ were mixed with boric acid flux (BM-0001-1, Fluxana) and fused in a Vulcan Fusion Machine (HD Electronic \& Elektrotechnik $\mathrm{GmbH}$ ) under flat molten glass discs.

For the wet chemical analysis of dissolved M1 powder first, $50 \mathrm{mg}$ of the sample was finely ground and then dissolved in a mixture consisting of $2 \mathrm{ml}$ bi-dist. $\mathrm{H}_{2} \mathrm{O}, 2 \mathrm{ml}$ hydrofluoric acid, and $2 \mathrm{ml}$ hydrochloric acid. The closed vessel was then ultrasonically treated at $100{ }^{\circ} \mathrm{C}$ for $10 \mathrm{~min}$, and subsequently another $20 \mathrm{~min}$ at $180^{\circ} \mathrm{C}$. The scandium standard was then added to the dissolved sample. An inductive coupled plasma atomic emission spectroscope (ICP-AES) (Arkos, Ametek) is used for elemental analysis with a plasma power of $140 \mathrm{~W}$ and a spray gas flow rate of $0.81 / \mathrm{min}$. 
The phase composition of the crystalline samples was determined by X-ray diffraction performed on a Bruker D8 Advance diffractometer using $\mathrm{Cu}-\mathrm{K} \alpha 1$ radiation. Alternatively, diffractograms were recorded on a PANalytical Empyrean with $\mathrm{Cu}-\mathrm{K} \alpha 1$ equipped with a Medipix PIXcel 3D Detector in $\Theta-\Theta$ geometry in the $2 \Theta$ range between $5-70^{\circ}$. The height of the source beam path was adjusted by a programmable divergence slit so that the sample was irradiated on a length of $12 \mathrm{~mm}$ over the whole $2 \Theta$ range. The width of the diffracted beam was limited to $10 \mathrm{~mm}$ by a fixed aperture. The horizontal divergence was minimized by $0.4 \mathrm{rad}$ Soller slits. The height of the reflected beam was adjusted by a programmable anti-scatter slit so that the diffracted beams were detected on a length of $12 \mathrm{~mm}$ on the sample over the whole $2 \Theta$ range. The samples were prepared either on an amorphous silicon plate or tableted as flatbed samples. The diffraction patterns of the activated materials were analyzed with the "TOPAS", software (v.2.1, Bruker AXS).

The specific surface areas were measured using Autosorb-6B-MP and Sorptomatic 1990 instruments (Quantachrome). Eleven points in the linear range of the nitrogen adsorption isotherm $(\mathrm{P} / \mathrm{P} 0=0.05-0.3)$ measured at $77 \mathrm{~K}$ were used to calculate the surface area according to the BET method. Before adsorption, the samples were degassed at $390 \mathrm{~K}$ or $523 \mathrm{~K}$ for $2 \mathrm{~h}$. The pore size distribution was determined with a Sorptomatic or a TriStar 3000 at $77 \mathrm{~K}$ by measuring $\mathrm{N}_{2}$ adsorption and desorption isotherms. Prior to measurement, the samples were degassed at $523 \mathrm{~K}$ for $2 \mathrm{~h}$. Data were analyzed using the Barrett-Joyner-Halenda method (BJH).

Catalytic high throughput performance tests were conducted in a 16-channel-flow-through stainless steel reactor. The amount of catalyst: $0.500 \mathrm{~g}$; flow rate $20 \mathrm{ml} / \mathrm{min} / \mathrm{channel}$; composition of the feed gas mixture: Propane: $\mathrm{Kr}_{2}: \mathrm{O}_{2}: \mathrm{He}_{2} \mathrm{O}=3: 1: 6: 70: 20 . \mathrm{Kr}$ has been used as internal standard facilitating the data analysis. Further details can be found in our previous contribution [56].

The kinetic tests of the catalysts in partial oxidation of propane at temperatures between 360 and $400{ }^{\circ} \mathrm{C}$ applying a contact time of $\mathrm{W} / \mathrm{F}$ of $2000 \mathrm{ml} / \mathrm{g}^{*} \mathrm{~h}$ and a molar ratio of propane/oxygen/steam $=1: 2: 13.6$ using nitrogen as balance $\left(\mathrm{C}_{3} \mathrm{H}_{8} / \mathrm{O}_{2} / \mathrm{H}_{2} \mathrm{O} / \mathrm{N}_{2}=3 / 6 / 41 / 50\right)$. The catalytic tests were carried out in a setup for selective oxidation (Integrated Lab Solutions, Berlin, Germany) using eight parallel fixed bed quartz reactors at atmospheric pressure. For the measurements, $300 \mathrm{mg}$ of the catalyst was diluted with $2.7 \mathrm{~g}$ of silicon carbide (ratio 1:10) for minimization of temperature gradients. Reactants and products were analyzed by online gas chromatography (Agilent 7890) achieving a mass balance of $99.7 \%$. Separation of the permanent gases $\mathrm{CO}, \mathrm{CO}_{2}, \mathrm{~N}_{2}$, and $\mathrm{O}_{2}$ was performed with a combination of a Plot-Q and a 
Plot-molsieve column connected to a thermal conductivity detector (TCD). Propane, propylene, acetic acid and acrylic acid were separated using a combination of a Plot-Q and a FFAP column connected to a flame ionization detector (FID).

\section{Theory / Calculation}

\subsection{Holographic Research Strategy (HRS)}

HRS optimization is based on the two-dimensional representation of experimental points in the Holographic Mapping (HM) [57,63]. The details of the HRS optimization are described elsewhere [57]. In HRS optimization, the initial experimental points (first catalyst generation) are created with maximum diversity in the given multidimensional and multivariate experimental space. The dimensions consist of predictor variables, i.e. composition of synthesis mixture, while the response variables are e.g. the propane conversion as well as the acrylic acid selectivity and yield. It has to be mentioned that acrylic acid yield is calculated as multiplication of conversion of propane and selectivity of acrylic acid [56]. For optimization purposes a combined objective function (OF) has been created as follows:

$$
\mathrm{OF}=6.35 \cdot \alpha_{\text {propane }} \cdot \mathrm{S}_{\text {acrylic acid }}+1.75 \cdot \mathrm{S}_{\text {acrylic acid }}+4.4 \cdot \alpha_{\text {propane }},
$$

where $\alpha_{\text {propane }}$ and $S_{\text {acrylic acid }}$ is the propane conversion and acrylic acid selectivity, respectively. This is a so-called "economic" objective function has been derived from a first process scheme which was developed by our cooperation partner, Scientific Design. In this way we wanted to balance the different effects of conversion and selectivity on the price of acrylic acid, and the second generated value product, steam, but also accounting for the price of propane. The higher is the OF the more economical is the production of AA. The forthcoming catalyst generations were appointed in the Holographic Maps by rectangular-shaped experimental regions $5 \times 5,4 \times 4$ and $2 \times 2$ in size around the best three hits of the respective preceding generations.

\subsection{Data analysis by means of Partial Least Square (PLS) regression}

PLS was used to reveal relationships between a response variable (acrylic acid yield) and predictor variables (composition of synthesis mixture) [56]. According to a general multiple linear regression model between the independent/predictor variables (X) and dependent/response variables $(Y), Y=X B+D$, where $B$ is a " $p$ " by "m" regression coefficient 
matrix while D is a " $m$ " by " $n$ " residual error matrix. The so-called X block matrix consists of " $m$ " independent variables for " $n$ " cases, leading to a matrix with size $\mathrm{n}$ by $\mathrm{m}$, while the Y block matrix consists of " $p$ " dependent variable for the " $n$ " cases resulting in a matrix with size $n$ by p. Nevertheless, variables both in Y and in X block are highly correlated. Therefore, different to general linear models, in PLS regression the goal is to create new variables (so-called principal components) as linear combinations of the original ones, so that there is no correlation between them. There is a detailed description of the model in [64].

Basically, PLS cannot discover cross effects between the main predictor variables, as it is a linear regression method. In order to overcome this problem, the simplest two-component interactions (multiplication/division between two predictor variables) are formed and the variables obtained in this way have been involved into PLS regression. Accordingly, the nonlinear cross effects are formally linearized and therefore PLS can be used for the formulation of a non-linear regression model.

In our methodology applied, the data set consisting of 250 data has been divided into training and validation sets. 188 data are selected for training while 62 for validation. The descriptor variables are the composition of the synthesis mixture while the predictor variable is the acrylic acid yield. Initially, the model is fitted for the training set involving all linear and cross effects. Using the residual E matrix, the modelling powers for all variables have been determined according the formula, Power $=1-\frac{S V_{j}}{S V_{j}^{0}}$, where standard deviation of an element of the residual E matrix $\left(\mathrm{SV}_{\mathrm{j}}\right)$ is related to its initial standard deviation $\left(\mathrm{SV}_{\mathrm{j}}^{0}\right)$. A variable is completely relevant if its modeling power is equal to 1 . Variables with low modeling power are of little relevance. Then cross effects are removed from the model one-by-one according to their modelling power, starting with the less relevant one and the validation error is monitored, expressed as mean square error between the measured and predicted acrylic acid yield in the validation set. The algorithm is stopped when validation error increased upon removal of a cross effect.

\subsection{Data analysis by means of Artificial Neural Networks}

Similarly, to PLS, Artificial Neural Networks (ANNs) have been used in order to establish quantitative correlation between independent variables (composition of the synthesis mixture) and catalytic performance (acrylic acid yield).

ANNs are non-linear regression models, hence there is no need for the formation of cross effects between the predictor variables as described above for PLS. In case of non-linearity in the experimental space, it may provide a better model than PLS can, if over-fitting is carefully 
monitored and avoided [61]. Nevertheless, PLS indicates the pronounced main effects that should be in good accordance to that detected by means of ANNs and therefore PLS provides a clue in validation of the results obtained by means of ANNs.

The methodology applied here has been described in detail elsewhere $[58,65]$. The available data have been divided into training, validation and test sets with 188, 31, and 31 samples, respectively. The process of training and validation has been done using the RPROP algorithm [67]. Training is stopped if the validation error increases for more than two consecutive epochs. Cundari et al. [67] have applied nineteen different networks topologies. Each kind of architecture has been trained 1000 times (each training step has been initialized with different, random node-to-node weights). According to the 19 different topologies applied, to the whole set consists of 19000 networks. This number was reduced to the best 100 networks, having the smallest mean square errors (MSEs) calculated for both training and validation sets. Finally, the best 100 networks have been involved into the Optimal Linear Combination [67], during which a so-called OLC-network has been created. The OLC-network has been combined with HRS in order to visualize the experimental space $[63,65]$. The predictive ability of the OLCnetwork was verified using the 31 data of the test set that has not been applied in the training and validation phase.

\section{Results and discussion}

\subsection{Optimization of the hydrothermal synthesis and M1 phase space}

The synthesis of the orthorhombic M1 phase with different metal compositions has been object of many studies in the last decades [60,68-73]. The abundant literature is consequence of the difficulty of preparing such complex metal oxide with high crystalline purity; i.e. avoiding the crystallization of any other of the many possible metal oxide byproducts. Among the different synthetic methods, hydrothermal synthesis is preferred because it allows a better control of parameters and it can yield single crystalline phases [72]. It is known that the M1 phase can be formed with a relatively wide metal stoichiometry, even as a two-component MoV oxide without $\mathrm{Nb}$ and $\mathrm{Te}$, but many synthesis parameters affect the final product in terms of crystalline purity and metal stoichiometry [60,71-73]. The highest impact in the final product lays on the temperature and duration of the hydrothermal step [60] and the redox potential of the reacting mixture $[60,74]$. 
In this context, a successful reproduction at large scale of the optimized catalytic material is not a trivial task. An important point of the scale up of the synthesis is the heat supply to the autoclave. While the high throughput synthesis method uses a microwave oven for the heating of a series of autoclaves, the hydrothermal synthesis of MoV-based mixed oxides is typically done at lab-, pilot-scale, and industrial plants in autoclaves with electric or double shell heating units. The use of microwaves brings core differences in the heat transfer process. With regular heating, thermal gradient effects are usually at play. Conversely, with the use of microwaves the conversion of energy into heat takes place simultaneously and evenly across the entire reacting volume [75,76]. This is translated into a faster and more efficient conversion of energy into heat, which will likely affect the rates of formation of the M1 phase precursor. Therefore, it is at first necessary to undertake a parameter space study of the hydrothermal synthesis conditions in a regularly heated autoclave, in order to establish the range of reaction conditions - synthesis temperature and duration- for which a high concentration of M1 phase can be expected. Once this is determined, the next step is the replication of the best hit from the catalyst library prepared by MW-heated synthesis - where metal stoichiometry and additives have been separately optimized.

Our synthesis parameter space study uses as starting point the hydrothermal synthesis as described in [60], with a fixed Mo:V:Te:Nb stoichiometry of 1:0.25:0.23:012. Fig. 1 shows a $2 \mathrm{D}$ contour plot with the concentration of M1 phase achieved after thermal treatment of $\mathrm{MoVTeNbO}_{\mathrm{x}}$ solids prepared by hydrothermal synthesis. The synthesis temperature was varied in the range of $180-220^{\circ} \mathrm{C}$ and synthesis duration from 1 to $48 \mathrm{~h}$. The use of a Hastelloy C22 autoclave allows studying a temperature region higher than in former works with Teflon-lined systems $[60,71,77]$.

Hydrothermal synthesis durations of only $3 \mathrm{~h}$ are sufficient to reach a high concentration of M1 crystalline phase at $175^{\circ} \mathrm{C}$ when the more efficient microwave-assisted heating is used [56]. However, it can be seen in Fig. 1 that in the double shell heated autoclave the duration required at $180{ }^{\circ} \mathrm{C}$ is above $35 \mathrm{~h}$. Indeed, extending the synthesis for $48 \mathrm{~h}$ yielded $80-90 \%$ purity in M1 phase for a broad range of synthesis temperatures $\left(180-200^{\circ} \mathrm{C}\right)$. Interestingly, the parameter space study shows that an increase of hydrothermal temperature from 180 to $190{ }^{\circ} \mathrm{C}$ allows for a dramatic reduction of the synthesis time. Indeed, it was found that purities of $>99 \% \mathrm{M} 1 \mathrm{can}$ be obtained in the range $190-210^{\circ} \mathrm{C}$ if the duration of the synthesis is limited to $10-12 \mathrm{~h}$. It can be concluded that an overall increase of ca. $15-30{ }^{\circ} \mathrm{C}$ in the synthesis temperature with respect to the microwave-heated synthesis makes up for the less efficient introduction of energy in the standard heated system. Another challenge of the synthesis in the double shell heated autoclave 
is the low specific surface area that can be achieved for the synthesized material. It scatters around $2 \mathrm{~m}^{2} \mathrm{~g}^{-1}$. Consequently, the propane conversion, as well as acrylic acid selectivity and yield is comparatively low $(10 \%, 42 \%$ and $4 \%$, respectively). In addition, to improve acrylic acid selectivity further, promoters will be considered in the following combinatorial approach.

\subsection{Library design and catalytic test}

Compositions of the synthesis mixture of the best three hits and the corresponding catalytic results in 5 generations are given in Table 5 . As the $1^{\text {st }}$ generation, the modifier-free, phasepure M1 synthesized at high $\mathrm{T}$ in a standard double shell heated autoclave was considered.

As emerges from results given in Table 5 there is a permanent increase in the yield and selectivity of acrylic acid in each generation up to the $4^{\text {th }}$ generation, while no further increase in the $5^{\text {th }}$ generation observed indicating the technological limit of the present set of variables applied. The results show that the best catalyst samples contain only four or five additional components beside the main four ones, i.e. Mo, $\mathrm{V}$, Te and $\mathrm{Nb}$. The best hit resulted in $58 \%$ yield of acrylic acid in the $4^{\text {th }}$ generation. The composition of the best hits in the $2^{\text {nd }}$ generation indicated that $\mathrm{Cr}$ and $\mathrm{Cu}$ have a negative influence on the AA yield. This indication was further supported by results obtained in the $3^{\text {rd }}$ generation. In this generation, negative effect of tungsten was also observed. These findings allow us to decrease the number of compositional variable down to five.

Fig. 2 shows the AA yield - conversion dependence in four generations. Generally, significant improvement in catalytic performance is achieved in subsequent generations. The excellent performance in the fourth generation is due to the pronounced increase in the selectivity of acrylic acid as there is only minor increase in the conversion value (see Table 5). It is interesting to note that the diversity in the performance of compositions decreased in subsequent generations. In the first generation the conversion values varied from 0 to 67 , while in the fourth generation the conversion range was relatively narrow, i.e. between 55 and 73 \% (Fig. 2). It has to be mentioned that the surface area of the best hits exceeds $10 \mathrm{~m}^{2} / \mathrm{g}$. This value is somewhat higher than that of the common M1 catalysts.

Data given in Table 5 show that only components (Mn, Ni, Co, CA and Glycol) are needed to achieve high yields of acrylic acid. It is very important to emphasize that all hits in the $3^{\text {rd }}$ and $4^{\text {th }}$ generations show selectivity values above $70 \%$ percent (see Table 5). Consequently, the improvement in the performance of designed catalyst is due to the significant increase in the value of propane conversion. This fact can also be seen in Fig. 2. 
Fig. 3 shows the correlation between the flow rates of the different products in the effluent gas mixture over different catalysts in each consecutive generation. As emerges from Fig. 3A, it is clear that $\mathrm{CO}$ and $\mathrm{CO}_{2}$ are formed in parallel reactions independent of the catalysts used.

According to Fig. 3B formation of acrylic acid and $\mathrm{CO}_{2}$ is correlated as well. However, it seems obvious that there can be two possible formation routes. In the parallel pathway, $\mathrm{CO}_{2}$ yields increased with increasing AA yields. The AA yield is strongly limited as large portion of the propane substrate is converted to $\mathrm{CO}_{2}$. The goal in an effective optimization process would be to change the "master curve" in such a way that the new catalysts would lead to high AA yield and simultaneously small $\mathrm{CO}_{2}$ formation. For the consecutive pathway to $\mathrm{CO}_{2}$, there are catalysts that obey this request already in the $2^{\text {nd }}$ generation. Over these catalysts, $\mathrm{CO}_{2}$ and acrylic acid seem to be formed in a consecutive reaction scheme. High concentrations of acrylic acid can only be formed on the expense of $\mathrm{CO}_{2}$ in this consecutive reaction. In this respect the $4^{\text {th }}$ generation was the most promising, the consecutive route is the dominating. Flow rate of $\mathrm{CO}_{2}$ and acrylic acid showed an inverse relation over the different catalysts in this generation.

\subsubsection{Holographic mapping (HM)}

$\mathrm{HM}$ is considered as the visualization of a multidimensional experimental space, i.e. twodimensional arrangement of predicted catalytic data. Both ANNs [63] or PLS [61] can be used for prediction, however, previous results indicated that ANNs, supposing they are not overfitted, are superior to PLS in revealing synergism between the variables [61]. Additionally, ANNs can be more precise than PLS in the evaluation of different non-linear effects. Therefore, in this study acrylic acid yield predicted by ANNs are visualized. These results are shown in Fig. 4. The corresponding levels of variables are given in Table 4. This mode of mapping allows differentiating between excellent and good catalyst compositions.

The mapping clearly shows the positive effect of all components and their concentration levels around the optimum (see red ellipse in Fig. 4A). This fact is well demonstrated in Fig. 4B, in which excellent compositions only appear at high levels of $\mathrm{Mn}$ and $\mathrm{Co}$, i.e. beneath the red line in Fig. 4B. It clearly shows that Mn and Co are key modifiers. However, Fig. 4A shows that the highest levels of Mn should be avoided, while Co has a positive effect in the whole concentration range. Ni has a positive effect only in its first and second levels. Citric acid (CA) has an optimum at its third and fourth levels, while ethylene glycol (Gly) is needed in its $1^{\text {st }}$ or $2^{\text {nd }}$ level, but it has no negative influence in the whole concentration range. The number of excellent experimental points decreases with the increase of the levels of Gly (see red ellipse in Fig. 4A). The optimum level of CA decreases at a high level of Gly. 


\subsubsection{PLS regression}

The regression coefficients (B) as defined in section 2.2. are listed in Table 6. They indicate that amongst the main variables $\mathrm{Mn}$, citric acid, ethylene glycol, and Co have positive effects on acrylic acid yield while $\mathrm{Ce}, \mathrm{Cr}, \mathrm{W}$ and $\mathrm{Cu}$ have considerable negative ones. Ni seems to be neutral. All these findings are in good accordance to those concluded when ANNs where used. Table 6 contains the relevant cross effects as well. As a starting set, all cross-effects, expressed in multiplications and divisions between the 5 main variables having positive or neutral effects, such as $\mathrm{Mn}, \mathrm{Ni}, \mathrm{CA}$, Gly and Co, have been formed, which led to 25 cross-effect-variables. Eventually, as a result of the selection-removal methodology applied, the 9 cross effects listed in Table 6 are involved into the final PLS model. The 5 main effects and their cross effects are discussed in the following.

$\mathrm{Mn}$ interacts with several other variables in the synthesis mixture. It is clear that the simultaneous presence of $\mathrm{Mn}$ and $\mathrm{Ni}$ is not advantageous as its multiplication has a negative effect on AA. In contrast to this, combination of Mn with ethylene glycol improve catalytic performance. The effect of $\mathrm{Mn} / \mathrm{CA}$ is neutral while $\mathrm{Mn} / \mathrm{Co}$ is strongly positive. The latter means that $\mathrm{Mn}$ to Co ratio should be kept at a relatively high value, even if both variables have positive effect alone. In summary, with respect to Mn we can conclude that it has to be applied at the highest level, while Ni and Co should be kept at low or medium levels.

$\mathrm{Ni}$ has a neutral effect and besides it has a negative quadratic effect $\left(\mathrm{Ni}^{2}\right)$, too, which means that within the investigated concentration range AA passes through a maximum with increasing $\mathrm{Ni}$ levels. Anyway, as it has a negative cross effect with $\mathrm{Mn}$, it can be completely omitted from the experimental space in good accordance with ANNs analysis.

The main linear effect of CA is positive, and it has a negative quadratic effect as well, suggesting an optimum in AA yield with increasing CA levels. Obviously, not the lowest level is the most advantageous, as $\mathrm{Mn} / \mathrm{CA}$ has a negative effect. In the presence of high levels of $\mathrm{Mn}$, the CA level has to be increased too, level 3 has to be applied.

Effect of Gly is quite similar to that of CA in many respects. Its quadratic effect is negative as well. Hence, an optimum is expected in the AA yield when Gly is increased within the investigated concentration range. Additionally, it has a positive cross effect with $\mathrm{Mn}$ and accordingly, it can be applied at higher levels in the presence of Mn. Level 4 seems to a good choice. 
The main effect of Co is positive and additionally it has a positive cross effect with Gly. However, as the $\mathrm{Mn} / \mathrm{Co}$ has a positive effect as well, one may expect the use of Co at relatively low values if $\mathrm{Mn}$ is present.

It can be said that PLS regression, when cross effects are involved, led to results and conclusions with respect to the effect of different variables quite similar to those obtained in the case of ANNs.

\subsection{First synthesis scale-up: laboratory reproduction of the best hit}

Since synthesis duration and temperature (and hence pressure) are the most impactful parameters in the product of a hydrothermal synthesis, it can be assumed that a $2 \mathrm{D}$ contour similar to the one in Fig. 1 could be obtained for other combinations of MoVNbTe metal stoichiometries and additives. Following this assumption, the hydrothermal synthesis conditions for the Premex $400 \mathrm{ml}$ double shell heated autoclave to reproduce the best hit were chosen to be temperature of $190{ }^{\circ} \mathrm{C}$ and $12 \mathrm{~h}$ duration, as obtained by the methodology shown in section 4.1. However, it should be noted that the different composition of the reacting mixture might have an influence as well on the formation of the M1 phase, because the chemical potential of the aqueous solution affects the type and concentration of polyoxomolybdate species in solution, which are key for the formation of M1 phase [74,78]. Therefore, the physicochemical properties and activity of the catalyst produced in the scale up needed to be carefully examined.

The total reaction volume in the Premex $400 \mathrm{ml}$ autoclave was $200 \mathrm{ml}$, and the concentration of salts was adjusted to $0.50 \mathrm{~mol}$ of $\mathrm{Mo} / \mathrm{L}$. Reactant and chemicals used for the synthesis were identical to those described in section 3.1.2. Their amounts were adjusted in order to achieve a MoVTeNb stoichiometry of 1:0.22:0.18:0.18 and the same M/Mo mol ratios as shown for the best hit in Table 5. Table 7 shows a comparison of the physico-chemical properties and catalytic performance of the best hit obtained in the microwave-heated high throughput autoclave and the reproduction of this catalyst in a standard double shell heated autoclave.

The concentrations of $\mathrm{Mn}, \mathrm{Ni}$ and Co additives in both catalysts do not deviate significantly. Regarding the $\mathrm{M} / \mathrm{Mo}$ ratios of the principal elements, a certain enrichment in $\mathrm{V}, \mathrm{Te}$ and $\mathrm{Nb}$ is detected in the best hit with respect to the nominal composition. This can signify that Mo was not completely incorporated into the solid and a part was lost in the mother liquor. Noticeably, the values obtained in the reproduction of the best hit are very close to the nominal composition. In any case, the crystalline composition of both samples is virtually identical. A concentration of ca. $85 \%$ M1 was achieved in both cases, while the main secondary crystalline phase 
corresponds to a $\mathrm{MMoO}_{4}$ where $\mathrm{M}$ is $\mathrm{Ni}, \mathrm{Co}$ or $\mathrm{Mn}$. Further evidence of the presence of this secondary phase was found by SEM-EDX (data not shown here). In the microwave-assisted high throughput preparation, small amounts of a $\mathrm{MMoTeO}_{6}$ were also detected.

Despite the similar chemical and crystalline composition, it was found that the material synthesized in a double shell heated autoclave achieved only ca. $60 \%$ of the activity of the catalyst prepared by microwave-assisted synthesis. It should be mentioned here that the BET surface area of the conventionally synthesized M1 is about $50 \%$ lower as compared to the M1 from the $\mu$-wave-assisted preparation. On the other hand, the high selectivity to acrylic acid was preserved. In order to determine the effect of the secondary crystalline phases on the activity, a pure $\mathrm{MnMoO}_{4}$ material was synthesized and tested in the selective oxidation of propane (data not shown). The material was found to be inactive under reaction conditions applied here. Therefore, the positive effect of $\mathrm{Ni}$, $\mathrm{Co}$ and $\mathrm{Mn}$ additives must lay in the doping of the M1 phase and not in the formation of the minority $\mathrm{MMoO}_{4}$ phase.

From the data summarized in Table 7, we conclude that the optimized M1 catalyst can be successfully reproduced in a double shell heated lab-scale autoclave once the hydrothermal conditions have been adjusted. The lower propane conversion achieved for the material prepared in the double shell heated autoclave can be attributed to a lower concentration of active sites per gram of catalyst, as a consequence of its $\sim 45 \%$ lower surface area (Table 7 ). As mentioned, the decrease in activity (ca. $40 \%$ ) detected for the reproduction of the best hit corresponds roughly to the decrease of surface area as measured by $\mathrm{N}_{2}$ isotherm (ca. $45 \%$ ).

\subsection{Scale-Up of the mixed oxide matrix phase into the kg-Range}

Before scaling-up the M1 recipe including all the promoters first trials were undertaken to scaleup successfully the M1 matrix oxide. The first major problem of the standard preparation procedure to be solved regards the availability of telluric acid typically used. Telluric acid is not available commercially in large scales and its production is highly dangerous as it involves the digestion of telluria with $\mathrm{H}_{2} \mathrm{O}_{2}$. Therefore, it is of highest priority to find a production route avoiding telluric acid. Finally, the cheapest route to such mixed metal oxide catalysts would only use oxides as starting materials and would completely avoid the more expensive soluble compounds used so far in the literature. Therefore, the hydrothermal synthesis method was optimized one more time starting from oxides only.

The finally obtained, scaled-up M1 catalyst had a BET surface area of $9 \mathrm{~m}^{2} / \mathrm{g}$, roughly twice as high as the laboratory trial (vide supra), a pore volume of $0.04 \mathrm{~cm}^{3} / \mathrm{g}$, and is characterized by the typical XRD pattern of the M1 phase as shown in Fig. 5. 


\section{Conclusions}

A detailed study of the synthesis parameter space for the classical hydrothermal synthesis of M1 from soluble compounds has shown that the use of temperatures in the range $190-210{ }^{\circ} \mathrm{C}$ allows formation of high purity M1 phase at relatively short synthesis times (below $12 \mathrm{~h}$ ). The stability and phase compositional regime of the M1 phase is now much better understood. Based on this information, an adjustment of the key synthetic parameters in the hydrothermal method has allowed transferring the synthesis of an optimized M1 catalyst from a $100 \mathrm{ml}$ microwave heated autoclave to a $400 \mathrm{ml}$ double shell heated autoclave. The properties of the material were virtually the same as for the optimized M1, with the exception of the surface area, which was smaller. The consequence is a decrease in the conversion per gram, although the high selectivity to acrylic acid remained intact.

Because the classical M1 synthesis suffers from a high molar ratio of ammonium ions, a new preparation route had to be developed for the high throughput optimization. Synthesis aids, citric acid and ethylene glycol were identified which allowed the use of $\mathrm{MoO}_{3}$ and $\mathrm{V}_{2} \mathrm{O}_{5}$ as starting materials. The results of the high throughput study again demonstrate the advantage of combinatorial and high-throughput methods for catalyst optimization. The goal to obtain catalyst compositions having AA yields around $60 \%$ has been achieved synthesizing and testing 250 catalysts in total. We could again show that Holographic Research Strategy is a very powerful optimization tool. Cross effects between the constituents of the synthesis mixture have been discovered by visualization of AA yield predicted by means of ANNs in Holographic maps. Additionally, formal linearization of cross effects was achieved in model building by means of Partial Least Square regression. It can be concluded that there is a quite acceptable agreement between the two data mining tools. The main positive effects were identified for $\mathrm{Mn}$, ethylene glycol, $\mathrm{Co}, \mathrm{Ni}$ and citric acid. Additionally, there is a remarkable positive synergism between $\mathrm{Mn}$ and ethylene glycol. Of course, this large set of catalysts could not be completely characterized, except for BET surface area needed for activity normalization. The full characterization study will be the topic of a future publication.

Moreover, two reaction pathways could be proposed from the high throughput performance data for formation of $\mathrm{CO}_{2}$ and acrylic acid. The parallel pathway obviously has a limitation in AA yield and therefore has to be suppressed. Successful development of catalysts leading to consecutive formation of these products was achieved within 5 generations. High AA yield was obtained when the consecutive step leading to $\mathrm{CO}_{2}$ was inhibited. 
The new hydrothermal method especially developed for the high throughput experiments still resorted to telluric acid and ammonium niobium oxalate. Especially telluric acid renders a largescale production of the M1 phase impossible as this chemical cannot be purchased in bigger, technical quantities. Hence, the synthesis recipe had to be further refined only using the cheapest, technically available chemicals, the oxides, which could be successfully scaled up into a 401 autoclave. This breakthrough development now renders possible the large-scale production of such complex MoVNbTe mixed oxide catalysts.

\section{Acknowledgement}

Partial financial support from grant KMOP-1.1.2-07/1-2008-0002 is greatly acknowledged.

\section{References}

[1] J.L. Callahan, R.K. Grasselli, W.R. Knipple, BE64114219640401, 1964.

[2] R.K.Grasselli, A.F. Miller, H.F. Hardman, US4323703, 1971.

[3] J.D. Burrington, C.T. Kartisek, R.K. Grasselli, J. Catal., 81 (1983) 489-498.

[4] I. Walzel, G. Mestl, S. Neumann, M. Pritzl, G. Donabauer, R.K. Grasselli, US9975111B2, 2013.

[5] "Acrylic Acid" in Kirk-Othmer Encyclopedia of Chemical Technology, Vol 1, John Wiley \& Sons, New York - Chichester - Toronto, 1991, pp. 287-314.

[6] "Acrylic Acid" in Ullmanns Encyclopedia of Industrial Chemistry, Vol. a1, VCH-Verlag, Weinheim, 1996/1997, pp. 161-184.

[7] X. Meng, P. Tsobanakis, J. Malsam, T. Abraham, WO2005003074, 2003.

[8] J.-L. Dubois; C. Duquenne, W. Hölderich, WO2006114506, 2005.

[9] M. Hatano, A. Kayo, EP0318295B1, 1987.

[10] M. Hatano, A. Kayo, US05049692A1, 1987.

[11] T. Ushikubo, I. Sawaki, K. Oshima, K. Inumaru, S. Kobayakawa, K. Kiyono, EP603836B1, 1992.

[12] K. Satoru, H. Hidenori, K. Masatoshi, W. Mamoru, EP0895809B1, 1997.

[13] F. Borgmeier, A. Tenten; H. Hibst, EP1335793B1, 2000. 
[14] S. Chaturvedi, A.M. Gaffney, S. Han, H.N. Le Dominique, R. Song, M.D. Heffner, E.M. Vickery, EP1192987B1, 2000.

[15] O. Machhammer, C. Adami, C. Hechler, P. Zehner, EP1642879B1, 2000.

[16] H. Hibst, F. Borgmeier, K.J. Müller-Engel, DE10359027A1, 2003.

[17] H. Hibst, F. Borgmeier, K.J. Müller-Engel, US2004147393A1, 2003.

[18] P. Hazin, EP1771405B1, 2004.

[19] C. Paparizos, M.J. Seely, J.F. Jr. Brazdil, B.C. Sutradhar, WO2009/048553A2, 2007.

[20] C.G. Lugmair, J. Zysk, R.K. Grasselli, WO2005000463A2, 2003.

[21] "ICIS Chem. Business 19-25 Nov 2012".

[22] J.L. Dubois, F. Desdevises, S. Serreau, D. Vitry, W. Ueda, US7345198B2, 2002

[23] O. Machhammer, K.J. Müller-Engel, M. Dieterle, US7524987B2, 2005.

[24] 9 Japan Chemical Daily, 6/20/2017.

[25] T. Ushikubo, Y. Koyasu, JP3484729 (B2), 1993.

[26] J.M. Lopez-Nieto, A.P. Botelly, M.I. Vazques-Navarro, A. Dejoz-Garcia, WO03/064035A1, 2002.

[27] J.F. Brazdil, R.J. George, B.I. Rosen, WO2005/018804A1, 2003.

[28] J.F. Brazdil, R.J. George, B.I. Rosen, WO2004/108277A1, 2003.

[29] D.A. Ryan, WO2006/130288A1, 2005.

[30] U. Dingerdissen, U. Rodemerck, D. Linke, S. Kolf, D. Herein, WO2007/118870A2, 2006.

[31] A.M. Gaffney, R. Gosh, R. Song, C.Y. Yeh, T. Langner, US2010/0255985A1, 2009.

[32] S.C. Arnold, A.M. Gaffney, R. Song, C.Y. Yeh, WO2010/115108A1, 2009.

[33] L.M. Kustov, A.V. Kucherov, T.N. Kucherova, E.D. Finashina, V.I. Isaeva, H. Cai, A. Krzywicki, WO2010/096909A1, 2009

[34] G. Inoue, WO2010/137747A1, 2009.

[35] A.M. Gaffney, R. Gosh, R. Song, C.Y. Yeh, T. Langner, US2010/0255986A1, 2009. 
[36] L.M. Kustov, A.V. Kucherov, E.D. Finashina, A.Y. Stakheev, I.M. Sinev, A. Krzywicki, US2011/0245571A1, 2010.

[37] L.M. Kustov, A.V. Kucherov, E.D. Finashina, V. Simanzhenkov, A. Krzywicki, CA2752409A1, 2011.

[38] L.M. Kustov, A.V. Kucherov, E.D. Finashina, V. Simanzhenkov, A. Krzywicki, US2013/0072737A1, 2011.

[39] S. Han, C.D. Frick, D.J. Martenak, WO2013/148006A1, 2012.

[40] U. Rodemerck, D. Linke, M. Strebelle, WO2013/026720A1, 2011.

[41] F. De Rooij, R.J. Schoonebeek J.J. Slot, M.J.F.M Verhaak, WO2013/164418A1, 2012.

[42] K.H. Hofmann, A. Meiswinkel, C. Thaller, H.-J. Zander, EP2716621A1, 2012.

[43] K.-H. Hofmann, A. Meiswinkel, C. Thaller, F. Winkler, H.-J. Zander, J.A. Lercher, D. Hartmann, A.C. Van Veen, M.C. Sanchez-Sanchez, DE102013014241A1, 2013.

[44] H.-J. Zander, F. Winkler, A. Meiswinkel, K.-H. Hofmann, C. Thaller, J.A. Lercher, D. Hartmann, A.C. Van Veen, M.C. Sanchez-Sanchez, WO2015/028121A1, 2013.

[45] A.N.R. Bos, R.J. Schoonebeek, M.J.F.M. Verhaak, WO2015/082598A1, 2013.

[46] A.N.R. Bos, R.J. Schoonebeek, F. Spies, M.J.F.M. Verhaak WO2015/082602A1, 2013.

[47] S. Han, C.D. Frick, D. Martenak, US2015/045582A1, 2013.

[48] F. De Rooji, R.J. Schoonebeek, J.J. Berg-Slot, M.J.F.M. Verhaak, US2015/119622A1, 2013.

[49] F. De Rooji, R.J. Schoonebeek, M.J.F.M. Verhaak, J.J. Berg-Slot, WO2014/154808A1, 2013.

[50] G. Mitkidis, M. San Roman-Macia; G. Van Rossum, R.J. Schoonebeek, WO2017/072086A1, 2015.

[51] A. Bos, G. Van Rossum, R. Schoonebeek, R. Stephens, M. Verhaak, WO2018/114900A1, 2016.

[52] G. Mestl, K. Wanninger, S. Neumann, WO2018141651A2, 2017.

[53] G. Mestl, K. Wanninger, D. Melzer, M. Sanchez-Sanchez, J. Tseglakova, J. Lercher, WO2018141652A1, 2017.

[54] G. Mestl, K. Wanninger, D. Melzer, M. Sanchez-Sanchez, J. Tseglakova, J. Lercher, WO2018141653A1, 2017.

[55] G. Mestl, K. Wanninger, D. Melzer, M. Sanchez-Sanchez, J. Tseglakova, J. Lercher, WO2018141654A1, 2017. 
[56] G. Mestl, J.I. Margitfalvi, L. Végvári, G.P. Szijjártó, A. Tompos, Appl. Catal. A: Gen., 474 (2014) 39.

[57] L. Végvári, A. Tompos, S. Göbölös, J.L. Margitfalvi, Catal. Today, 81 (2003) 517-527.

[58] A. Tompos, J.L. Margitfalvi, E. Tfirst, L. Végvári, M.A. Jaloull, H.A. Khalfalla, M.M. Elgarni, Appl. Catal. A: Gen., 285 (2005) 65-78.

[59] A. Tompos, J.L. Margitfalvi, L. Végvári, E. Tfirst, Comb. Chem. High Throughput Screening, 10 (2007) 121.

[60] A. Celaya Sanfiz, W.T. Hansen, F. Girgsdies, O. Timpe, E. Rödel, T. Ressler, A. Trunschke, R. Schlögl, Top. Catal., 50 (2008) 19-32.

[61] G.P. Szijjártó, A. Tompos, K. Héberger, J.L. Margitfalvi, Comb. Chem. \& High Throughput Screen., 15 (2012) 105-113.

[62] J.L. Margitfalvi, A. Tompos, E. Tálas, M. Hegedús, in: S. Smith (Ed.), Catalysis of Organic Reactions, New York, Marcel Dekker, Inc., 2006, pp. 303-314.

[63] A. Tompos, J.L. Margitfalvi, L. Vegvari, A. Hagemeyer, A.F. Volpe, C.J. Brooks, Top. Catal., 53 (2010) 100-107.

[64] P. Geladi, B.R. Kowalski, Anal.Chim. Acta, 185 (1986) 1-17.

[65] A. Tompos, M. Hegedűs, J.L. Margitfalvi, E.G. Szabo, L. Végvári, Appl. Catal. A: Gen., 334 (2008) 348-356.

[66] M. Riedmiller, H. Braun, Proc. IEEE Int. Conf. On Neural Network, 586-591, 1993.

[67] J.T.R. Cundari, J. Deng, Y. Zhao, Ind. Eng. Chem. Res., 40 (2001) 5475-5480.

[68] H. Tsuji, K. Oshima, Y. Koyasu, Chem. Mater., 15 (2003) 2112-2114.

[69] P. Botella, E. García-González, J.M. López Nieto, J.M. González-Calbet, Solid State Sci., 7 (2005) 507-519.

[70] P. Botella, P. Concepción, J.M. López Nieto, Y. Moreno, Catal. Today, 99 (2005) 51-57.

[71] F. Ivars, P. Botella, A. Dejoz, J.M. López Nieto, P. Concepción, M.I. Vázquez, Top. Catal., 38 (2006) 59-67.

[72] W. Ueda, D. Vitry, T. Kato, N. Watanabe, Y. Endo, Res. Chem. Intermed., 32 (2006) 217-233.

[73] Y.V. Kolenko, W. Zhang, R.N. d'Alnoncourt, F. Girgsdies, T.W. Hansen, T. Wolfram, R. Schlögl, A. Trunschke, ChemCatChem, 3 (2011) 1597 - 1606. 
[74] M. Sadakane, N. Watanabe, T. Katou, Y. Nodasaka, W. Ueda, Angew. Chem. Int. Ed., 46 (2007) 1493-1496.

[75] G.D. Stefanidis, A. Navarrete Munoz, G. Sturm, A. Stankiewicz, Rev. Chem. Eng., 30 (2014) 233 259.

[76] J.A. Gerbec, D. Magana, A. Washington, and G.F. Strouse J. Am. Chem. Soc., 127 (2005) 15791 15800.

[77] D. Vitry, Y. Morikawa, J.L. Dubois, W. Ueda, Appl. Catal. A: Gen., 251 (2003) 411-424.

[78] M. Sanchez-Sanchez, F. Girgsdies, M. Jastak, P. Kube, R. Schlögl, A. Trunschke, Angew. Chem. Int. Ed. , 51 (2012) 7194-7197. 


\section{Figure Captions:}

Figure 1. 2D contour map of the M1 phase crystalline composition of solids by hydrothermal synthesis in a double shell heated autoclave. Major by-phases are indicated in the corresponding areas.

Figure 2. AA yield - conversion dependence in five generations. $1^{\text {st }}$ generation, $2^{\text {nd }}$ generation, $\triangle 3^{\text {rd }}$ generation, $\times 4^{\text {th }}$ generation, $\odot 5^{\text {th }}$ generation

Figure 3. Correlation between the flow rates of constituents, $\mathrm{CO}_{2}(\mathrm{~A})$ and acrylic acid (B), in the effluent gas mixture. $\bullet 1^{\text {st }}$ generation, $\square 2^{\text {nd }}$ generation, $\triangle 3^{\text {rd }}$ generation, $\times 4^{\text {th }}$ generation, $5^{\text {th }}$ generation.

Figure 4. Two forms of holographic maping after four generations. Colour codes: Mn $\mathrm{Ni}-$ , Citric acid Co Gly -

Figure 5. Diffraction pattern of the M1 phase obtained from the hydrothermal synthesis starting from oxides only. 
Table 1. Variable levels in the $1^{\text {st }}$ generation

\begin{tabular}{lllllllllll}
\hline \multicolumn{1}{l}{ Levels } & \multicolumn{8}{c}{ Concentration/ molar ratio to Mo } \\
& $\mathrm{Mn}$ & $\mathrm{Ni}$ & $\mathrm{Ce}$ & $\mathrm{CA}^{1}$ & $\mathrm{Gly}^{2}$ & $\mathrm{Cr}$ & $\mathrm{Co}$ & $\mathrm{W}$ & $\mathrm{Cu}$ \\
\hline $1^{\text {st }}$ & 0.01 & 0.00 & 0.0000 & 0.050 & 0.000 & 0.0000 & 0.0000 & 0.00 & 0.0000 \\
$2^{\text {nd }}$ & 0.03 & 0.04 & 0.0025 & 0.075 & 0.025 & 0.0025 & 0.0025 & 0.04 & 0.0025 \\
$3^{\text {rd }}$ & 0.05 & 0.08 & 0.0250 & 0.100 & 0.050 & 0.0250 & 0.0250 & 0.08 & 0.0250 \\
$4^{\text {th }}$ & 0.07 & & 0.0500 & & 0.075 & 0.0500 & 0.0500 & & 0.0500 \\
\hline
\end{tabular}

${ }^{1}$ Citric Acid; ${ }^{2}$ Ethylene Glycol

Table 2. Variable levels in the $2^{\text {nd }}$ and $3^{\text {rd }}$ generations

\begin{tabular}{llllllllll}
\hline \multicolumn{1}{l}{ Levels } & \multicolumn{8}{c}{ Concentration/ molar ratio to Mo } \\
& $\mathrm{Mn}$ & $\mathrm{Ni}$ & $\mathrm{Ce}$ & $\mathrm{CA}^{1}$ & $\mathrm{Gly}^{2}$ & $\mathrm{Cr}$ & $\mathrm{Co}$ & $\mathrm{W}$ & $\mathrm{Cu}$ \\
\hline $1^{\text {st }}$ & 0.01 & 0.00 & 0.00 & 0.050 & 0.000 & 0.0000 & 0.0000 & 0.00 & 0.0000 \\
$2^{\text {nd }}$ & 0.03 & 0.02 & & 0.075 & 0.025 & 0.0025 & 0.0025 & 0.02 & 0.0025 \\
$3^{\text {rd }}$ & 0.05 & 0.04 & 0.100 & 0.050 & 0.0050 & 0.0250 & 0.04 & 0.0050 \\
$4^{\text {th }}$ & & 0.06 & & 0.075 & & 0.0500 & 0.06 & \\
$5^{\text {th }}$ & & 0.08 & & & & & & 0.08 & \\
\hline
\end{tabular}

${ }^{1}$ Citric Acid; ${ }^{2}$ Ethylene Glycol

Table 3. Variable levels in the $4^{\text {th }}$ and $5^{\text {th }}$ generations

\begin{tabular}{llllllllll}
\hline \multicolumn{1}{l}{ Levels } & \multicolumn{8}{c}{ Concentration/ molar ratio to Mo } \\
& $\mathrm{Mn}$ & $\mathrm{Ni}$ & $\mathrm{Ce}$ & $\mathrm{CA}^{1}$ & $\mathrm{Gly}^{2}$ & $\mathrm{Cr}$ & $\mathrm{Co}$ & $\mathrm{W}$ & $\mathrm{Cu}$ \\
\hline $1^{\text {st }}$ & 0.06 & 0.00 & 0.00 & 0.0625 & 0.025 & 0.00 & 0.0250 & 0.00 & 0.00 \\
$2^{\text {nd }}$ & 0.07 & 0.02 & & 0.0750 & 0.050 & & 0.0375 & & \\
$3^{\text {rd }}$ & 0.08 & 0.04 & & 0.0875 & 0.075 & 0.0500 & \\
$4^{\text {th }}$ & 0.09 & 0.06 & & & 0.100 & & 0.0625 & & \\
$5^{\text {th }}$ & & 0.08 & & & & & & & \\
\hline
\end{tabular}

${ }^{\mathrm{T}}$ Citric Acid; ${ }^{2}$ Ethylene Glycol 
Table 4. Variable levels used in holographic mapping

\begin{tabular}{llllll}
\hline \multicolumn{2}{c}{ Levels } & \multicolumn{5}{c}{ Concentration/ molar ratio to Mo } \\
& $\mathrm{Mn}$ & $\mathrm{Ni}$ & $\mathrm{CA}^{1}$ & $\mathrm{Gly}^{2}$ & $\mathrm{Co}$ \\
\hline $1^{\text {st }}$ & 0,0500 & 0,0000 & 0,0125 & 0,0500 & 0,0000 \\
$2^{\text {nd }}$ & 0,0625 & 0,0200 & 0,0250 & 0,0625 & 0,0250 \\
$3^{\text {rd }}$ & 0,0750 & 0,0400 & 0,0375 & 0,0750 & 0,0500 \\
$4^{\text {th }}$ & 0,0875 & & 0,0500 & 0,0875 & 0,7500 \\
$5^{\text {th }}$ & 0,1000 & & 0,0625 & 0,1000 & 0,1000 \\
\hline
\end{tabular}

${ }^{1}$ Citric Acid; ${ }^{2}$ Ethylene Glycol

Table 5. Compositions of the synthesis mixture of the best three hits in 5 generations $(\mathrm{Mo} / \mathrm{V} / \mathrm{Te} / \mathrm{Nb}=1 / 0.22 / 0.18 / 0.18)$.

\begin{tabular}{ccrrrrrrrrrrr}
\hline Gen & \multicolumn{1}{c}{ Concentration/molar ratio to Mo } & \multicolumn{4}{c}{ AA yield $^{1}$} & AA Sel $^{2}$ \\
& $\mathrm{Mn}$ & $\mathrm{Ni}$ & $\mathrm{Ce}$ & $\mathrm{CA}^{3}$ & $\mathrm{Gly}^{4}$ & $\mathrm{Cr}$ & $\mathrm{Co}$ & $\mathrm{W}$ & $\mathrm{Cu}$ & $\%$ & $\%$ \\
\hline $0^{\text {th }}$ & 0 & 0 & 0 & 0 & 0 & 0 & 0 & 0 & 0 & 4 & 42 \\
\hline $1^{\text {st }}$ & 0.03 & 0 & 0 & 0.05 & 0.05 & 0.0025 & 0.025 & 0 & 0.0025 & 37 & 57 \\
& 0.01 & 0.08 & 0 & 0.05 & 0 & 0 & 0.0025 & 0 & 0.0025 & 37 & 58 \\
& 0.03 & 0.08 & 0 & 0.1 & 0.025 & 0.0025 & 0.05 & 0.08 & 0 & 36 & 57 \\
\hline $2^{\text {nd }}$ & 0.03 & 0.08 & 0 & 0.1 & 0.025 & 0.005 & 0.05 & 0.08 & 0 & 45 & 70 \\
& 0.03 & 0.08 & 0 & 0.1 & 0.025 & 0 & 0.05 & 0.08 & 0 & 43 & 66 \\
& 0.01 & 0.08 & 0 & 0.05 & 0 & 0 & 0.0025 & 0 & 0.005 & 43 & 66 \\
\hline $3^{\text {rd }}$ & 0.07 & 0 & 0 & 0.075 & 0.075 & 0 & 0.0375 & 0 & 0 & 53 & 73 \\
& 0.07 & 0 & 0 & 0.05 & 0.025 & 0 & 0.0375 & 0 & 0 & 50 & 73 \\
& 0.07 & 0 & 0 & 0.05 & 0.025 & 0 & 0.05 & 0 & 0 & 49 & 75 \\
\hline $4^{\text {th }}$ & 0.08 & 0.02 & 0 & 0.075 & 0.075 & 0 & 0.0375 & 0 & 0 & 58 & 80 \\
& 0.07 & 0 & 0 & 0.075 & 0.075 & 0 & 0.0375 & 0 & 0 & 56 & 79 \\
& 0.09 & 0.02 & 0 & 0.0625 & 0.025 & 0 & 0.05 & 0 & 0 & 56 & 81 \\
\hline $5^{\text {th }}$ & 0.09 & 0.02 & 0 & 0.0875 & 0 & 0 & 0.0375 & 0 & 0 & 53 & 78 \\
& 0.08 & 0.02 & 0 & 0.1 & 0.025 & 0 & 0.0375 & 0 & 0 & 52 & 72 \\
& 0.08 & 0.02 & 0 & 0.0625 & 0.075 & 0 & 0.0375 & 0 & 0 & 52 & 66 \\
\hline 1
\end{tabular}

${ }^{1}$ Acrylic Acid yield; ${ }^{2}$ Acrylic Acid selectivity; ${ }^{3}$ citric acid; ${ }^{4}$ glycerol

${ }^{\#}$ Synthesis parameters as described in section 2.1.2 
Table 6. Effect of different variables on Acrylic acid yield

\begin{tabular}{|c|c|c|c|c|c|c|c|c|c|}
\hline \multicolumn{10}{|c|}{ Main effects } \\
\hline Variables & $\mathrm{Mn}$ & $\mathrm{Ni}$ & $\mathrm{Ce}$ & $\mathrm{CA}$ & Gly & $\mathrm{Cr}$ & Co & $\mathrm{W}$ & $\mathrm{Cu}$ \\
\hline $\mathrm{B}^{2}$ & 0,074 & $-0,004$ & $-0,273$ & 0,094 & 0,083 & $-0,151$ & 0,059 & $-0,087$ & $-0,202$ \\
\hline \multicolumn{10}{|c|}{ Cross effects } \\
\hline Variables & $\mathrm{MnNi}$ & $\mathrm{Ni}^{2}$ & MnGL & $\mathrm{CA}^{2}$ & Gly $^{2}$ & $\mathrm{GL} * \mathrm{Co}$ & $\mathrm{Co}^{2}$ & $\mathrm{Mn} / \mathrm{CA}$ & $\mathrm{Mn} / \mathrm{Co}$ \\
\hline $\mathrm{B}^{2}$ & $-0,075$ & $-0,055$ & 0,133 & $-0,099$ & $-0,133$ & 0,167 & $-0,215$ & $-0,042$ & 0,159 \\
\hline
\end{tabular}

${ }^{1}$ Modelling power; ${ }^{2}$ Regression coefficients in $\mathrm{Y}=\mathrm{BX}+\mathrm{E}$

Table 7. Chemical and crystalline composition, surface area and catalytic performance of best hit from $5^{\text {th }}$ generation and its reproduction in a standard autoclave. ${ }^{\#}$

$5^{\text {th }}$ generation best

hit $^{\mathrm{a}} \quad$ Reproduction $^{\mathrm{a}}$

\begin{tabular}{lcc}
\hline Heating mode & Microwaves & Thermostatic oil \\
\hline Chemical composition & & \\
(XRF) & & \\
V/Mo & 0.24 & 0.21 \\
Te/Mo & 0.20 & 0.18 \\
$\mathrm{Nb} / \mathrm{Mo}$ & 0.20 & 0.21 \\
$\mathrm{Mn} / \mathrm{Mo}$ & 0.054 & 0.066 \\
$\mathrm{Co} / \mathrm{Mo}$ & 0.028 & 0.033 \\
$\mathrm{Ni} / \mathrm{Mo}$ & 0.013 & 0.019 \\
\hline
\end{tabular}

Crystalline phase

composition

M1

$84 \%$

$88 \%$

$\mathrm{MMoO}_{4}$

$10 \%$

$12 \%$

$\mathrm{MTeMoO}_{6}$

$6 \%$

\begin{tabular}{lcc}
\hline Surface area BET $\left(\mathrm{m}^{2} / \mathrm{g}\right)$ & 9 & 5 \\
\hline Propane conversion $(\%)^{\mathrm{b}}$ & 58 & 34 \\
\hline Selectivity to AA $(\%)^{\mathrm{b}}$ & 72 & 73 \\
\hline
\end{tabular}

${ }^{a}$ Nominal composition shown in Table $5 \ldots$

${ }^{\mathrm{b}}$ Activity measured at $400{ }^{\circ} \mathrm{C}$, reaction conditions as in section 3.2.2.

\#Synthesis parameters as described in section 2.1.2 
Figures

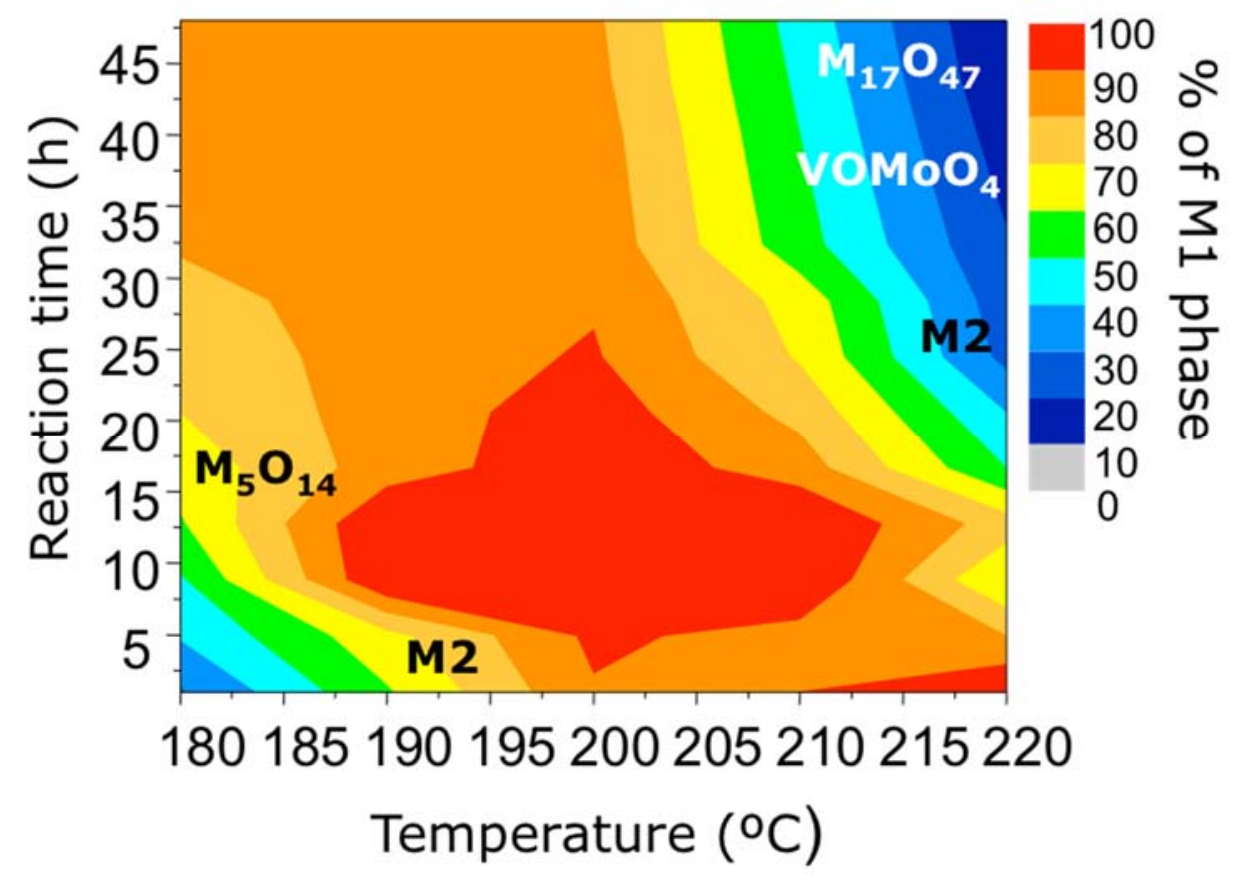

Figure 1. 2D contour map of the M1 phase crystalline composition of solids by hydrothermal synthesis in a double shell heated autoclave. Major by-phases are indicated in the corresponding areas. 


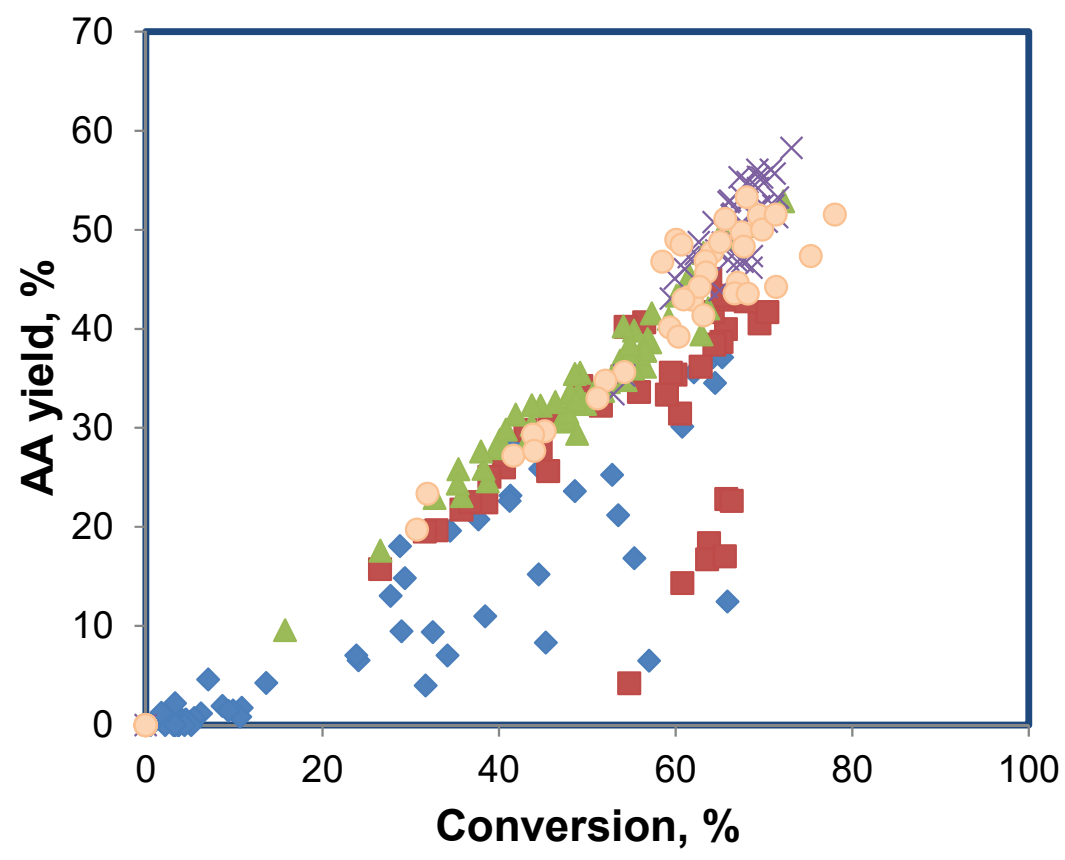

Figure 2. AA yield - conversion dependence in five generations. $1^{\text {st }}$ generation, $2^{\text {nd }}$ generation, $\triangle 3^{\text {rd }}$ generation, $\times 4^{\text {th }}$ generation, $\circ 5^{\text {th }}$ generation
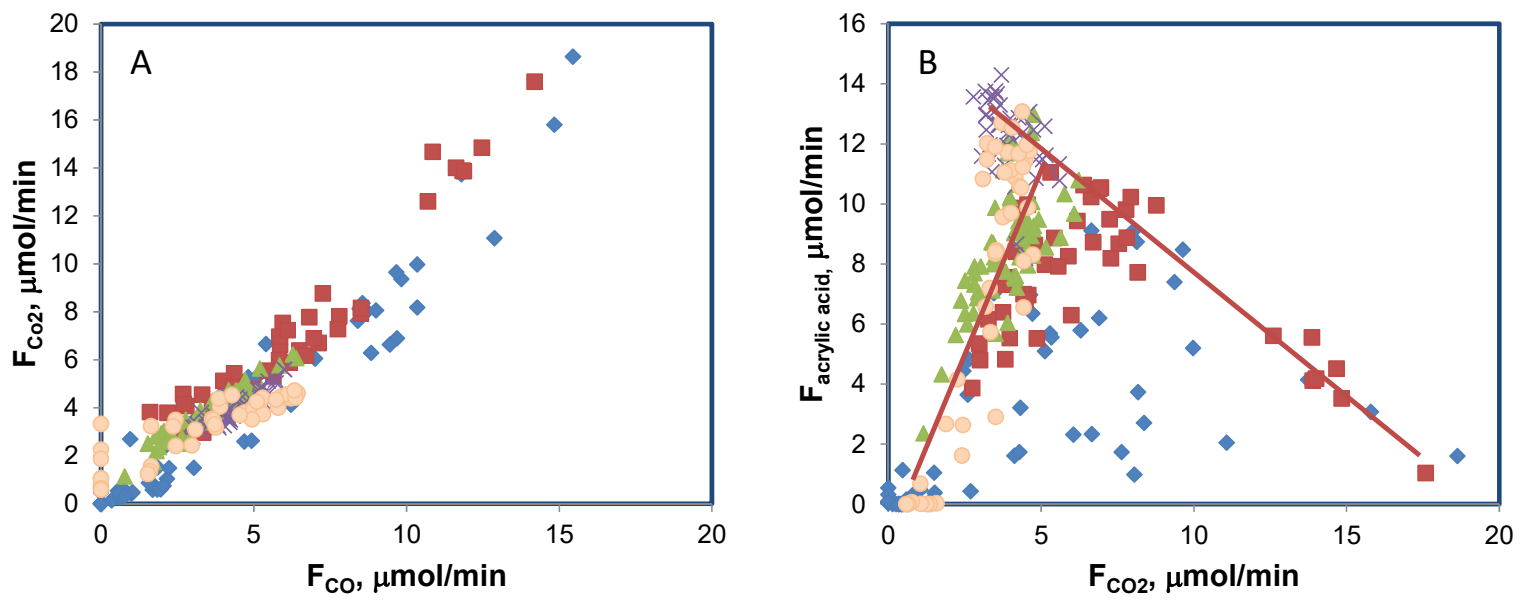

Figure 3. Correlation between the flow rates of constituents, $\mathrm{CO}_{2}$ (A) and acrylic acid (B), in the effluent gas mixture. $1^{\text {st }}$ generation, $\square 2^{\text {nd }}$ generation, $\triangle 3^{\text {rd }}$ generation, $\times 4^{\text {th }}$ generation, $5^{\text {th }}$ generation. 

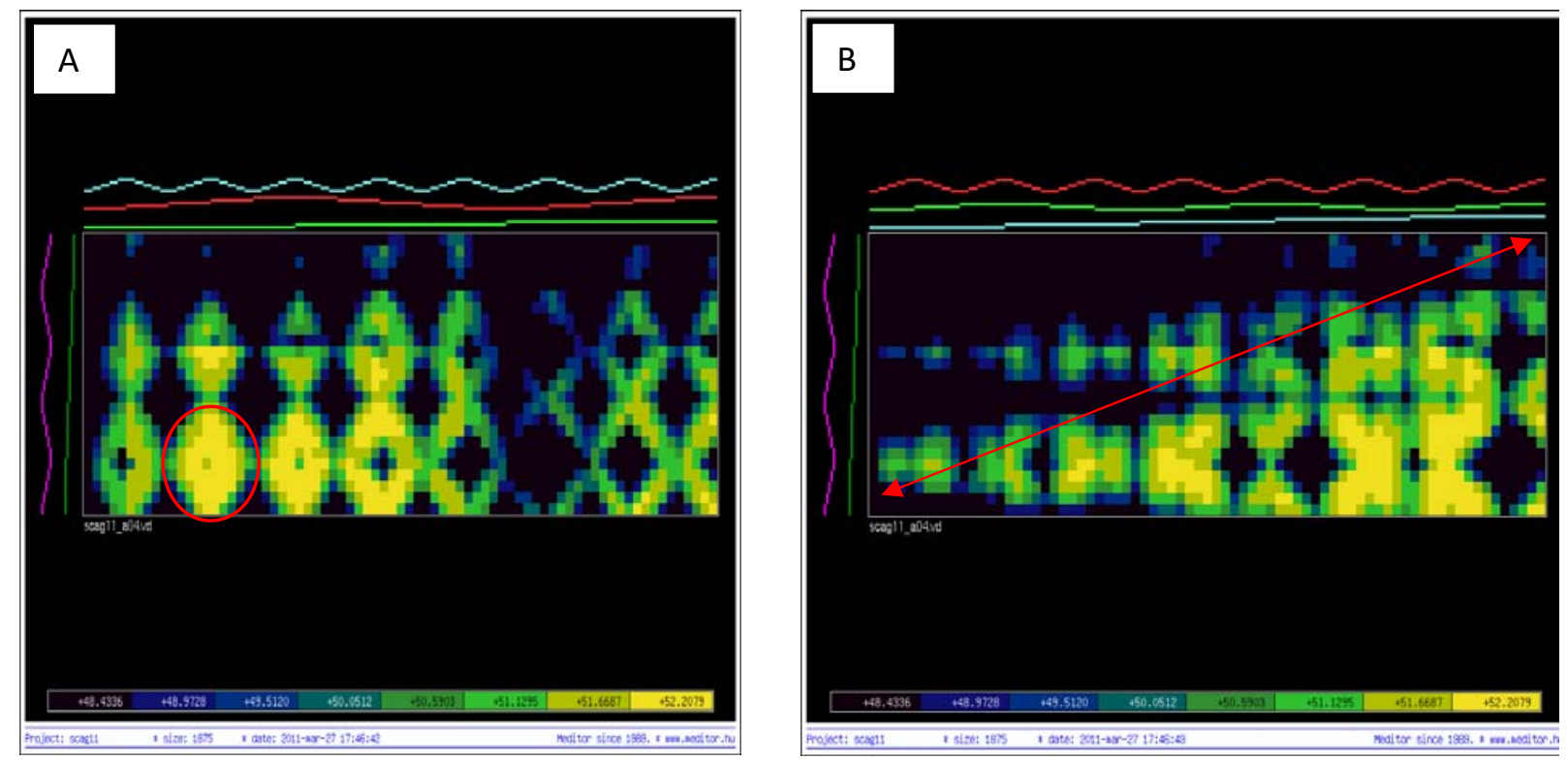

Figure 4. Two forms of holographic maping after four generations. Colour codes: Mn $\mathrm{Ni} \mathrm{-} \_$, Citric acid - —, Co - $\_$, Gly - 


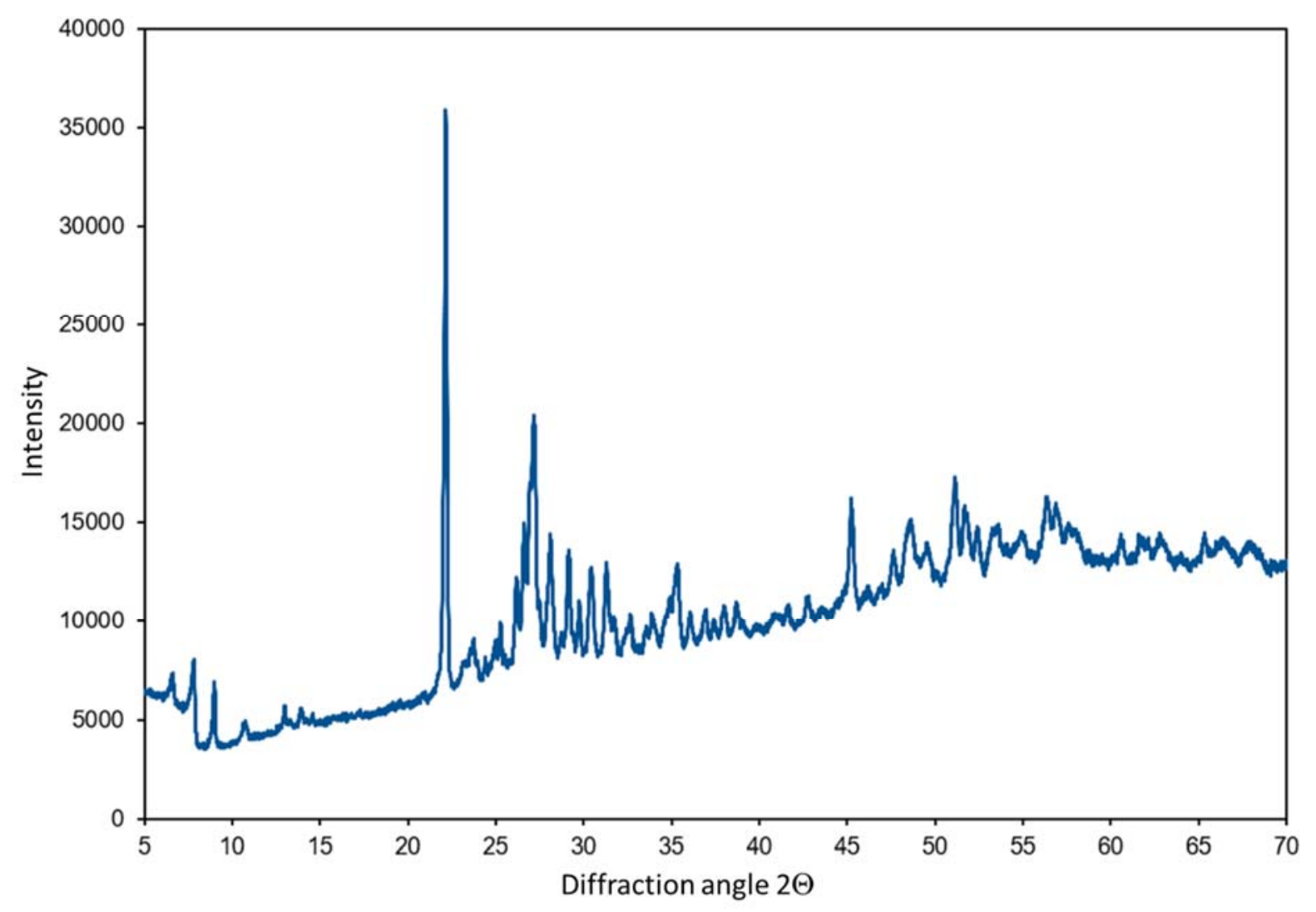

Figure 5. Diffraction pattern of the M1 phase with the Mo-related metal composition, $\mathrm{Mo}_{1} \mathrm{~V}_{0.3} \mathrm{Nb}_{0.1} \mathrm{Te}_{0.1}$ as obtained from the hydrothermal synthesis starting from oxides only. 